\title{
ELABORAÇÃO DE FIAMBRES COM AS CARNES BRANCA E ESCURA DE FRANGO'
}

\author{
M. GRANER ${ }^{2}$
}

RESUMO: 0 presente trabalho teve como objetivo específico a obtenção de fiambres com as carnes branca (do peito) e escura (das coxas e pernas) de frango, separadamente. Os cortes foram desossados manualmente e às carnes, após limpeza e corte, foram adicionados ingredientes não cárneos e aditivos, sendo elas moídas após 12 h. $O$ processamento térmico foi realizado em defumador até a temperatura interna de $71^{\circ} \mathrm{C}$. Foram obtidos fiambres curados e defumados com boa qualidade sensorial, adequado nível de proteína e baixo conteúdo calórico, do tipo semi-conserva. O rendimento foi maior na elaboração do fiambre de carne branca, o qual foi preferido na avaliação sensorial, em relação ao produto de carne escura.

Termos para indexação: carne de frango, fiambre

\section{CIIICKEN LOAVES PREPARED WITI BROILER LIGHT AND DARK MEAT}

ABSTRACT: Chiken loaves were prepared with light and dark meat from broiler and deboned breasts and legs. The meat was cut, cured, ground, smoked and pasteurized (until $71^{\circ} \mathrm{C}$ ). The yield was greater for the loaf prepared with light meat, which was also ranked first in sensory analysis. The light and the dark meat loaves had the following chemical compositions: moisture 70.6 - 71.0\%; protein $22.0-20.2 \%$; moisture/protein ratio 3.2 - 3.5; fat 4.0 - 4.5\%; sodium chloride $2.4-2.5 \%$; sodium nitrite $51.5-69.0 \mathrm{ppm}$; pH $6.1-6.25$, respectively. Index Terms: poultry products, chicken baves.

\section{INTRODUÇÃO}

Vários fatores contribuiram para 0 desenvolvimento de produtos à base de carne de aves, nos Estados Unidos da América (MOUNTNEY, 1966): disponibilidade de carne de aves leves; menor preço da carne de aves, em relação a outras carnes; desenvolvimento de equipamento para desossa mecânica; aperfeiçoamento no processamento, no armazenamento e no marketing; e aumento da demanda por produtos de preparo fácil e rápido. Nesse país, em meados da década de 80 , produtos elaborados com carne de aves eram vendidos a preços competitivos e até inferiores aos elaborados com as carnes suína ou bovina, e conquistavam uma faixa crescente do mercado, devido á propaganda enfatizando seu valor nutricional (DRAPER, 1984).

No Brasil, em 1973, SCHNEIDER já afirmava que galos, galinhas e aves de segunda teriam em salsicharia uma forma para seu melhor aproveitamento e, segundo SCHNEIDER et al. (1981), em 1979 já era bem sentida a necessidade da indústria procurar não se restringir ao beneficiamento da carne de aves e sua conservação pelo frio. Nos últimos 10 anos, foram lançados no mercado diversos produtos à base de carne de aves.

Entre os derivados que podem ser obtidos com a carne de aves encontram-se os fiambres que, segundo - "Diccionario de la Academia" de Espanha são produtos que, depois de assados ou cozidos, são resfriados e consumidos frios (SANZ EGAÑA, 1967). Fiambre, afiambrado e pão-de-carne são sinônimos (SÃo PAULO, 1978).

Alguns trabalhos sobre a elaboração de fiambres com carne de aves tem sido publicados no Brasil. GRANER (1973) obteve fiambre com a carne mista de galinhas leves descartadas da postura, estudando o efeito de algumas variáveis de processamento sobre propriedades organoléticas, físicas e químicas do produto.

SCHNEIDER et al. (1981) elaboraram embutidos defumados e cozidos em estufa, com carne mista de frango e parte desta matéria-prima substituída

\footnotetext{
${ }^{1}$ Parte do trabalho realizado com auxilio financeiro da Secretaria da Indústria, Ciência e Tecnologia do Estado de São Paulo.

${ }^{2}$ Departamento de Ciência e Tecnologia Agroindustrial da E.S.A. "Luiz de Queiroz" da Universidade de São Paulo - 13418-900-PIRACICABA,SP.
} 
por carne bovina ou bovina e suína, utilizando também farinha texturizada de soja.

GRANER (1987) estudou a elaboração de fiambre utilizando emulsão obtida com carne mista e gordura de frango, com e sem pele, obtendo um produto curado e defumado.

ROÇA et al. (1988b) utilizaram gordura suína em proporção variada para a obtenção de fiambre com a carne de frango mista, moída e curada; o produto foi cozido em banho-maria.

Os mesmos autores (ROÇA et al., 1988a) elaboraram fiambre com as carnes branca e escura de frango, não trituradas, obtendo produtos curados e cozidos em banho-maria.

O presente trabalho é parte de um estudo que teve como objetivo amplo o aproveitamento de partes comestíveis de aves na elaboração de produtos diversos, como formas alternativas de utilização dessa carne, visando benefícios para as etapas de produção, transformação, distribuição e consumo . O objetivo específico do trabalho foi a utilização das carnes branca e escura de frango, moídas, para a obtenção de fiambres curados e defumados.

\section{MATERIAL E METODOS}

Como ingredientes cárneos, foram utilizadas carnes branca (do peito) e escura (das pernas e coxas) e gordura (de todas as regiōes da carcaça), separadas manualmente de carcaças resfriadas de frango, adquiridas em estabelecimento comercial de Piracicaba, SP, e procedentes de abatedouro sob inspeção federal.

As carnes branca e escura, separadamente, após limpeza, foram cortadas em pequenos pedaços (4-6 $\mathrm{cm}$ ), acondicionadas em sacos de polietileno e congeladas a $-25^{\circ} \mathrm{C}$ por 12 dias. A gordura, após limpeza, foi moída através de disco com orifícios de 9 $\mathrm{mm}$ de diâmetro, acondicionada em sacos de polietileno e congelada a $-25^{\circ} \mathrm{C}$. Para análise química, porções de cada ingrediente cárneo foram separadas após limpeza e corte, homogeneizadas, acondicionadas em frascos de vidro e congeladas a $-25^{\circ} \mathrm{C}$.

Para a elaboração dos fiambres, as carnes branca e escura foram descongeladas a $0^{\circ} \mathrm{C}$ durante $48 \mathrm{~h}$ e a gordura, durante 12 horas. As formulações utilizadas na elaboraçao dos fiambres encontram-se na Tabela 1. Os ingredientes e aditivos (exceto o ácido ascórbico) foram juntados às carnes branca e escura, misturando-se bem, e o material deixado a $0^{\circ} \mathrm{C}$ por 12h. Adicionou-se então o ácido ascórbico, dissolvido em água. As carnes, assim tratadas, foram moídas através de discos com orifícios de 9 e $5 \mathrm{~mm}$ de diâmetro.

Tabela 1. Formulação utilizadas na elaboração dos fiambres (porcentagens)

\begin{tabular}{||lcc||}
\hline \multirow{2}{*}{ ou Aditivos } & \multicolumn{2}{c|}{ Carne } \\
\cline { 2 - 3 } Carne limpa & Branca & Escura \\
Gordura moída & 95 & 100 \\
Total Parcial & 5 & - \\
Gelo triturado e água & 10 & 100 \\
Sal (NaCl) refinado & 2,5 & 5 \\
Açúcar (sacarose) & & \\
refinado & 0,1 & 0,1 \\
Nitrito de sódio & 0,015 & 0,015 \\
Fosfato* & 0,05 & 0,05 \\
Pimenta branca em pó & 0,1 & 0,1 \\
Glutamato & & 0,1 \\
monoss6dico* & 0,1 & 0,05 \\
Ácido ascórbico & 0,05 & 107,9 \\
\hline Total Geral & 112,9 & \\
\hline
\end{tabular}

\section{* Produto comercial}

As pastas obtidas foram transferidas para formas descartáveis de alumínio e defumadas a $60-70^{\circ} \mathrm{C}$ por 1 hora e a $70-80^{\circ} \mathrm{C}$ por $2 \mathrm{~h}$ e $15 \mathrm{~min}$ (até que a temperatura interna dos produtos atingisse $71^{\circ} \mathrm{C}$ ).

Os produtos foram resfriados à temperatura ambiente $\mathrm{e}$, em seguida, a $0^{\circ} \mathrm{C} \mathrm{c}$, após acondicionamento em folhas de alumínio e sacos de politileno, congelados a $-25^{\circ} \mathrm{C}$ por 30 dias. Para análise química, meia peça correspondente a cada formulação foi separada após defumação e resfriamento, homogeneizada, acondicionada em frascos de vidro e congelada.

Para análise química, as amostras foram descongeladas a $0^{\circ} \mathrm{C}$ por $36 \mathrm{~h}$ (o pH e o teor de nitrito de sódio foram determinadas antes do congelamento). O teor de umidade foi determinado por método da AOAC (HORWITZ, 1970). O teor de proteína foi determinado por uma combinação de métodos: macro- 
Kjeldahl (JACOBS, 1958), para a digestão da amostra, e micro-Kjeldahl (HORWITZ, 1970), para a destilação do nitrogênio. $O$ teor de matéria graxa foi determinado pelo método de Kelley et al. (1954). A determinação do $\mathrm{pH}$ foi realizada com um potenciômetro digital $\mathrm{em}$ uma mistura, em partes iguais, de amostra e água recémdestiladas. $O$ teor de nitrito de sódio foi determinado pelo método fotocolorimétrico do reagente de Griess modificado e o de cloreto de sódio, por titulometria (HORWITZ, 1970).

Para avaliação sensorial, os produtos foram descongelados a ${ }^{\circ} \mathrm{C}$ durante $48 \mathrm{~h}$, fatiados e servidos frios a um grupo de 10 provadores previamente selecionados. Foi utilizada uma escala estruturada de 5 pontos com base em recomendação do INSTITUTE OF FOOD TECHNOLOGISTS (1981), para avaliação da cor, da textura, da suculência e do sabor. Os valores atribuídos aos fiambres foram submetidos à análise da variância (teste F) (GOMES, 1987). Aos provadores foi solicitado também que ordenassem os produtos, de acordo com a sua qualidade geral; a tabela de KAHAN et al. (1973) foi utilizada para verificação de significância no teste de ordenação.

\section{RESULTADOS E DISCUSSÃO}

Os rendimentos na obtenção das carnes branca (do peito) e escura (das coxas e pernas) encontram-se na Tabela 2. No preparo das carnes (limpeza e corte) houve uma perda maior $(7,6 \%)$ para a carne escura, em relação à branca $(0,6 \%)$, devida principalmente à remoção de tendões, no primeiro caso.

$\mathrm{Na}$ Tabela 3 encontram-se os valores obtidos na análise química dos ingredientes cárneos utilizados. Os resultados, para as carnes do peito e das coxas e pernas, são semelhantes aos da compilação de POSATI (1979); para a gordura, foi encontrado um menor teor de umidade e um maior teor de matéria-graxa. $\mathrm{O} \mathrm{pH} \mathrm{da}$ carne escura foi maior que o da carne branca, com valores semelhantes aos encontrados por WLADYKA \& DAWSON (1968).

$\mathrm{Na}$ defumação e pasteurização, seguidas de resfriamento, houve uma perda de peso ligeiramente superior no caso da carne branca, em relação à escura (Tabela 4), porém sem comprovação estatística. Essa diferença poderia ser explicada pelo menor $\mathrm{pH}$ da carne branca, uma vez que este fator afeta a capacidade de retenção de água da carne (LAWRIE, 1985). O rendimento final, em relação ao peso da carne, foi maior para a carne branca $(102 \%)$, em relação à escura (87\%), o que se explica em parte pela maior perda na limpeza e corte desta última (Tabela 2).
TABELA 2. Rendimentos na elaboração de fiambres com as carnes branca (do peito) e escura (das coxas e pernas) de frango de corte.

\begin{tabular}{||lcccc||}
\hline \multirow{2}{*}{ Fase } & \multicolumn{2}{c}{ Carne Branca } & \multicolumn{2}{c||}{ Carne Escura } \\
\cline { 2 - 5 } & Peso g & $\%$ & Peso g & $\%$ \\
\hline $\begin{array}{l}\text { Carcaças } \\
\text { Carne } \\
\text { desossa- } \\
\text { da sem } \\
\text { pele }\end{array}$ & 19.485 & - & 19.485 & - \\
$\begin{array}{l}\text { Carne } \\
\text { limpa, } \\
\text { cortada }\end{array}$ & 3.375 & 99,41 & 3.105 & 92,41 \\
$\begin{array}{l}\text { Carne } \\
\text { moída cl } \\
\text { ingredien } \\
\text { tes não } \\
\text { cárneos }\end{array}$ & 3.945 & 116,20 & 3.310 & 98,51 \\
$\begin{array}{l}\text { Fiambre } \\
\text { Fiand }\end{array}$ & 3.470 & 102,21 & 2.925 & 87,05 \\
\hline
\end{tabular}

Obs.: Os pesos da carne moída e do fiambre foram ajustados, admitindo-se a utilização de toda a carne limpa.

Tabela 3. Composição química dos ingredientes cárneos utilizados.

\begin{tabular}{||lccc||}
\hline Componente & $\begin{array}{c}\text { Carne } \\
\text { branca }\end{array}$ & $\begin{array}{c}\text { Carne } \\
\text { escura }\end{array}$ & Gordura \\
\hline Umidade (\%) & 74,86 & 74,48 & 23,59 \\
$\begin{array}{l}\text { Proteína (\%) } \\
\text { Relação Umi- } \\
\text { dade/Proteína }\end{array}$ & $3,33,50$ & 19,79 & 3,32 \\
$\begin{array}{l}\text { Matéria graxa } \\
(\%)\end{array}$ & 1,00 & 4,25 & 73,50 \\
pH & 5,81 & 6,21 & 6,07 \\
\hline
\end{tabular}


Tabela 4. Perda de peso na defumação a quente dos fiambres, seguida de resfriamento.

\begin{tabular}{||ccccc|}
\hline \multirow{2}{*}{ Carne } & \multirow{2}{*}{ Forma } & \multicolumn{2}{c|}{ Peso dos Fiambres (g) } & Perda de \\
\cline { 2 - 5 } & & Antes da defumação & Após a defumação & \begin{tabular}{c} 
peso (\%) \\
\hline \multirow{2}{*}{ Branca }
\end{tabular} \\
\cline { 2 - 5 } & 2 & 550 & 490 & 10,91 \\
& 3 & 550 & 485 & 11,82 \\
& Média & 553,3 & 490 & 12,50 \\
\hline \multirow{2}{*}{ Escura } & 1 & 530 & 488,4 & 11,74 \\
& 2 & 520 & 475 & 10,38 \\
& 3 & 540 & 460 & 11,54 \\
& Média & 530,0 & 480 & 11,11 \\
\hline
\end{tabular}

$\mathrm{Na}$ Tabela 5 encontra-se a composição química dos fiambres. $O$ valor nutricional dos produtos está associado principalmente ao seu teor de proteína de boa qualidade; além disso, o teor de gordura é baixo, proporcionando $36-40,5 \mathrm{kcal} / 100 \mathrm{~g}$, pela oxidação deste componente. A relação umidade/proteína, no fiambre de carne branca, foi inferior a $3,5 \mathrm{e}$, no de carne escura, foi praticamente igual a este valor, que é o limite superior para embutidos cozidos no País (BRASIL, 1980). O teor de umidade dos produtos, juntamente com o teor de cloreto de sódio e o pH, indicam que os mesmos são semi-conservas (para a sua conservação em estado não congelado, os fiambres devem ser embalados sob vácuo e refrigerados). $O$ teor de nitrito de sódio apresentou-se menor no fiambre de carne branca, em relação ao de carne escura; esta diferença pode ser devida à diferença de $\mathrm{pH}$ entre os produtos.

Os resultados da avaliação sensorial dos fiambres, pelo teste da escala estruturada, encontram-se na Tabela 6. Quanto à cor, houve diferença acentuada entre os fiambres de carne branca e os de carne escura, em função da maior concentração de pigmento nesta última; todavia, a média dos pontos atribuídos ao fator foi a mesma, nos dois casos (os provadores levaram em consideração a diferença de matéria-prima). Na avaliação da textura, da suculência e do sabor, as médias dos pontos favorecem o produto eleborado com a carne branca, mas a diferença não foi estatisticamente significativa. Todavia, quando se solicitou aos provadores que ordenassem os fiambres quanto à sua qualidade geral, verificou-se uma preferência significativa $(p<0,05)$ pelo produto de carne branca, que, no teste anterior, foi classificada entre bom e muito bom.

Tabela 5 - Avaliação sensorial dos fiambres.

\begin{tabular}{||ccc||}
\hline \multirow{2}{*}{ Componente } & \multicolumn{2}{c|}{ Fiambre } \\
\cline { 2 - 3 } & Carne branca & Carne escura \\
\hline $\begin{array}{l}\text { Umidade (\%) } \\
\text { Proteína (\%) }\end{array}$ & 70,56 & 71,03 \\
$\begin{array}{l}\text { Relação umi- } \\
\text { dade/proteína }\end{array}$ & 31,96 & 20,16 \\
$\begin{array}{l}\text { Matéria graxa } \\
\text { (\%) }\end{array}$ & 4,00 & 3,52 \\
$\begin{array}{l}\text { Cloreto de } \\
\text { sódio (\%) }\end{array}$ & 2,40 & 4,50 \\
$\begin{array}{l}\text { Nitrito de } \\
\text { sódio (ppm) }\end{array}$ & 51,50 & 2,47 \\
pH & 6,06 & 6,25 \\
\hline
\end{tabular}


Tabela 6. Avaliação sensorial dos fiambres.

\begin{tabular}{|cccccc|}
\hline Fiambre & Cor & Textura & Suculência & Sabor & Qualidade Geral \\
Carne branca & 4,50 & 4,20 & 4,40 & 4,40 & 4,37 \\
Carne escura & 4,50 & 3,50 & 3,90 & 4,00 & 3,97 \\
\hline
\end{tabular}

Obs.: Foi utilizada uma escala de 5 pontos: muito bom (5); bom (4); regular (3); ruim (2); muito ruim (1). Os valores para a qualidade geral são médias.

\section{CONCLUSÕES}

- Fiambres de frango, elaborados com a carne branca e com a escura, separadas manualmente dos ossos, curados e defumados, apresentaram qualidade sensorial aceitável.

- O fiambre de carne branca é mais aceitável, sob o ponto de vista sensorial, que o de carne escura.

- O rendimento é maior na obtenção do produto de carne branca, em relação ao de carne escura.

- Os produtos obtidos apresentaram nível adequado de proteína de boa qualidade e baixo conteúdo calórico (baixo teor de gordura).

- A conservação dos produtos deve ser feita sob vácuo e refrigeração ou por congelação.

\section{REFERENCIAS BIBLIOGRÁFICAS}

BRASIL. Ministério da Agricultura. Regulamento da inspeção industrial e sanitária de produtos de origem animal. Brasilia, Ministério da Agricultura, 1980. 166p.

DRAPER, J.E. Processamento de carnes de aves. In: SIMPÓSIO SOBRE ECONOMIA, CIÊNCIA E TECNOLOGIA DA CARNE, São Paulo, 1984. São Paulo, Grupo Kienast \& Kratschner Lopesco/Codac/USP, 1984. p.2.

GOMES, F.P. Curso de Estatística experimental. São Paulo, Nobel, 1987. 467p.

GRANER, M. Efeito de algumas variáveis de processamento sobre propriedades organoléticas, físicas e químicas de massa obtida com a carne de poedeiras. Anais da Escola Superior de
Agricultura "Luiz de Queiroz", Piracicaba, 31:133-46, 1974.

GRANER, M. Elaboração de fiambre com emulsão de carne mista e gordura de frango (Gallus gallus), sem e com pele. Anais da Escola Superior de Agricultura "Luiz de Queiroz", Piracicaba, 44: 273-97, 1987.

HORWITZ, W. ed. Official methods of analysis of the Association of Offical Analytical Chemists. Washington, AOAC, 1970. 1015p.

INSTITUTE OF FOOD TECHNOLOGISTS. Sensory evaluation guide for testing food and beverage products. Food Technology, Chicago, 35(11): 509, 1981.

KAHAN, C.; COOPER, D. PAPAVASILIOU, A.; KRAMER, A. Expanded tables for determining significance differences for ranked data. Food Technology, Chicago, 27(5): 61, 64-5, 68-9, 1973.

KELLEY,D.C.; GUERRANT, R.E.; MACKINTOSH, D.L. A study of methods os testing and sampling for the determination of fat content of ground meat. Food Technology, Chicago, 8(6): 273-6, 1954.

LAWRIE, R.A. Meat Science. Oxford, Pergamon, 1985. 267p.

MOUNTNEY, G.J. Poultry products technology. Westport, AVI, 1966. 264p.

POSATI, L.P., coord. Composition of foods; poultry products. Washington, Consumer and 
ROÇA, R.DE O.; SERRANO, A. DE M.; BONASSI, I.A. Composição química e características sensoriais de fiambres elaborados com carne de coxa e peito de frango. Boletim da Sociedade Brasileira de Ciência e Tecnologia de Alimentos, Campinas, 221/2: 79-85, 1988a.

ROÇA, R. DE O.; SERRANO, A. DE M.; BONASSI, I.A. Utilização do toucinho na elaboração de fiambre de carne de frango. Ciência e Tecnologia de Alimentos, Campinas, 8(1): 6776, 1988 .

SÃo PAULO (ESTADO). Leis, decretos, etc. Decreto $\mathrm{n}^{\circ} 12.486$ de 20 de outubro de 1978. Diário Oficial do Estado, São Paulo, 21 de outubro de 1978. p. 1-42. aprova normas téenicas especiais relativas a alimentos e bebidas.

SCHNEIDER, I.S. Processamento industrial de aves e seus subprodutos, São Paulo, Editora Brasileira de Avicultura, 1973. 100p.

SCHNEIDER, I.S.; SANTOS, J.C.; SERRANO, A. de $M$. Processamento de carne de ave adicionada de farinha texturizada de soja. I. Embutidos defumados. Boletim da Sociedade Brasileira de Ciência e Technologia de Alimentos, Campinas, 15(1): 47-65, 1981.

SANZ EGAÑA, C. Enciclopédia de la carne. Madrid, Espasa-Calpe, 1967, 1086p.

WLADYKA, E.V. \& DAWSON, L.E. Proximate composition of thawed chicken meat and drip after storage. Poultry Science, Ithaca, 47(4): 1111-5, 1968.

Trabalho entregue para publicação em 20.09.91 Trabalho aprovado para publicação em 26.11.91 